Kamiński Piotr, Jankowska Paula, Jankowski Krzysztof, Nogalski Adam. Epidemiology of genitourinary trauma in lubelskie voivodeship in Poland from 2006 to 2018. Journal of Education, Health and Sport. 2020;10(9):415-421. eISSN 2391-8306. DOI http://dx.doi.org/10.12775/JEHS.2020.10.09.049

https://apcz.umk.pl/czasopisma/index.php/JEHS/article/view/JEHS.2020.10.09.049

https://zenodo.org/record/4035874

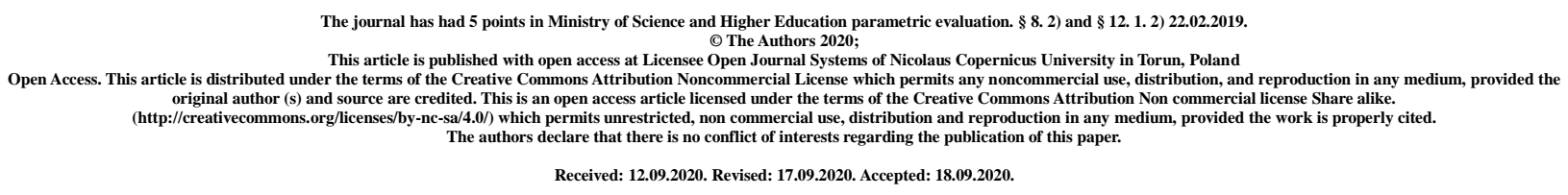

\title{
Epidemiology of genitourinary trauma in lubelskie voivodeship in Poland from 2006 to 2018
}

\author{
Piotr Kamiński, Paula Jankowska, Krzysztof Jacek Jankowski, Adam Nogalski
}

Piotr Kamiński

Affiliation Medical University of Lublin

Country Poland

Bio Statement

Chair and Department of Trauma Surgery and Emergency Medicine

Principal contact for editorial correspondence.

Paula Jankowska

Affiliation Medical University of Lublin

Country Poland

Bio Statement Chair and Department of Family Medicine

Krzysztof Jankowski

Affiliation Medical University of Lublin

Country Poland

Bio Statement Chair and Department of Family Medicine

Adam Nogalski

Affiliation Medical University of Lublin

Country Poland

Bio Statement Chair and Department of Trauma Surgery and Emergency Medicine

Title and Abstract 


\begin{abstract}
Introduction

Accidents and injuries are a major challenge for modern medicine. According to EUROSTAT data from 2016, accidents were the fifth most frequent cause of death among citizens of the European Union countries. Injuries of the urogenital-tract represent about $10 \%$ of all injuries, thanks to epidemiological analysis it is possible to continuously improve the effects of their treatment.
\end{abstract}

Aim

The aim of this study is to analyze the epidemiology of urogenital-tract injuries in 2006-2018 in Poland, in the region of Lublin Voivodeship, and to compare them with other papers on a similar subject.

\title{
Material and methods
}

The retrospective analysis was carried out on all patients with S-T diagnosis according to ICD-9 treated in hospitals in the Lublin Voivodeship in 2006-2018. The analysis was based on statistical data collected by the National Institute of Public Health - National Institute of Hygiene. There were 934 patients selected. The collected material was analyzed statistically using the STATISTICA 13.1 program.

\section{Results}

Out of 934 patients the vast majority were men $(n=782,83.73 \%)$, the remaining part of analyzed population was women $(n=152,16.27 \%)$. The average age of the analyzed group was 33 years 5 months, injuries were most common in 15-30 years old group. Mortality of urogenital-tract injuries in the analyzed group was $0.75 \%$. The most frequent injuries were to the external genitals $(55.4 \%)$ followed by renal $(29.66 \%)$ and urethra $(5.56 \%)$ bladder $(3.43 \%)$. Urinary injuries were very rare.

\section{Conclusions}

Injuries to the urogenital-tract most often involve young men. They are relatively rare and their mortality rate is low. External genital trauma is the most common injury to the urogenital-tract, while renal injury is the most common within the urinary tract. Occasionally injuries to other organs of the urinary tract occur. The main mechanism of injury is blunt but within the lower urinary tract a significant role is played by iatrogenic injuries.

\section{Key words: urogenital; trauma; epidemiology}

\section{Introduction}

Accidents and injuries are a major challenge for modern medicine. Apart from their obvious consequences, in the form of individual dramas of the victims, a big problem is their socioeconomic consequences, in the form of lost years of work and the necessity to pay social benefits. According to EUROSTAT data from 2016, accidents were the fifth most common cause of death among citizens of European Union countries [1]. Injuries are estimated to cause 5 million deaths worldwide [2]. According to the WHO report of 2016, they mostly concern men aged 15-49 years [3].

Of all injuries, about $10 \%$ are urogenital-tract injuries and also affect mainly young men [4,5]. In most cases they are not life-threatening, but may involve serious, distant complications. Constant analysis of the epidemiology and effects of injury treatment allows to focus on appropriate patient management, which significantly affects the effects of treatment of these patients. The aim of this study is to analyze the epidemiology of urogenital-tract injuries in 2006-2018 in Poland, in the region of Lublin Voivodeship, and to compare them with other papers on a similar subject. 


\section{Material and methods}

The retrospective analysis was carried out on all patients with S-T diagnosis according to ICD-9 treated in hospitals of Lublin Voivodeship in 2006-2018. Lublin Voivodeship is the third largest Voivodeship in Poland with a total area of $25122 \mathrm{~km} 2$. It is inhabited by 2108270 people [6]. It is a typically agricultural region, however, there are also large production plants here. A database of patients was created on the basis of statistical data collected by the National Institute of Public Health - National Institute of Hygiene, it included 678389 patients. Among these patients, 934 patients with diagnoses according to ICD-9 concerning urogenital-tract injuries were identified. The collected data were analyzed statistically using the STATISTICA 13.1 program.

\section{Results}

Of the 934 patients, the vast majority were male $(n=782,83.73 \%)$, while the remaining part of analyzed population was female $(n=152,16.27 \%)$. The average age of the analyzed group was 33 years 5 months, among men the average age was 33 years 6 months and among women - 33 years 3 months. The age structure of this population was presented in Figure 1. Death occurred only in 7 cases, which gives a total mortality rate of urinary injuries in the analyzed period of $0.75 \%$.

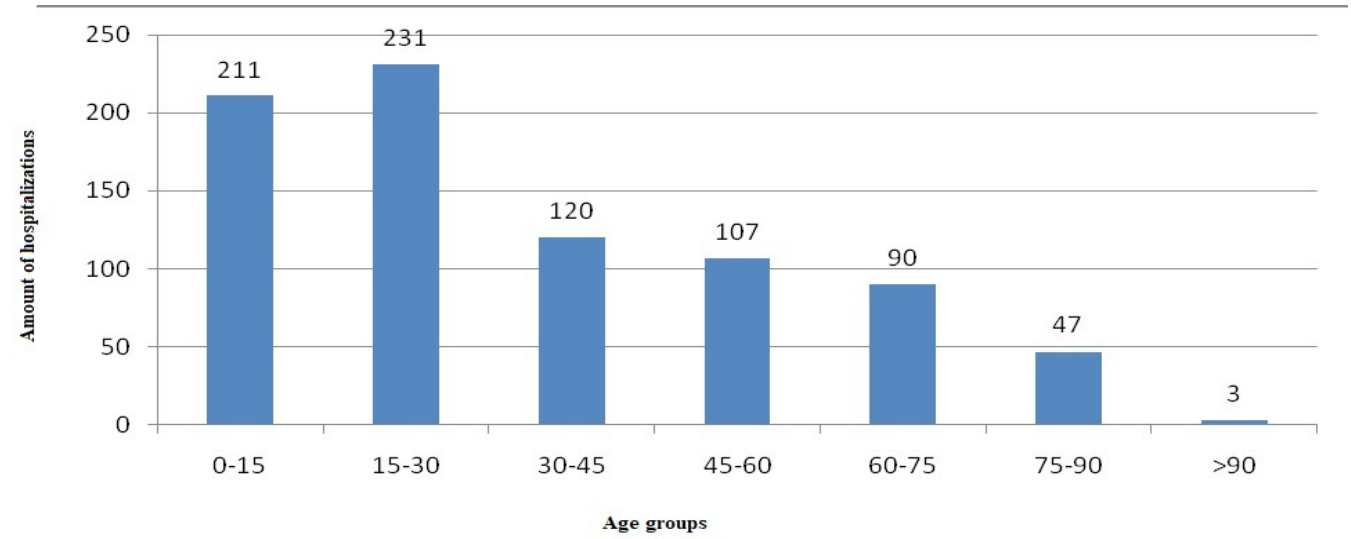

Fig. 1. Age structure in the analysed population 
The structure of injured organs has been shown in Figure 2.

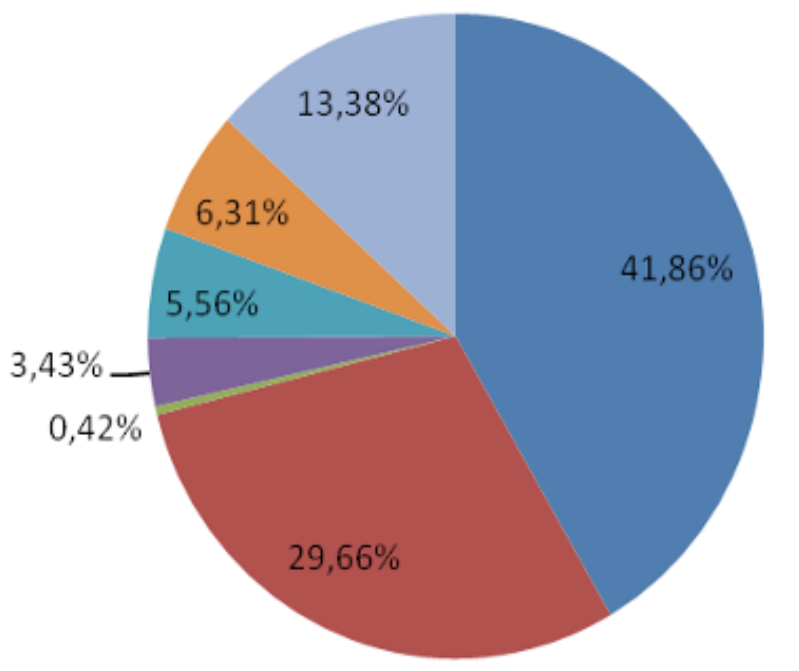

External genitalia

Kidney

n Ureter

Bladder

Urethra

Foreign body of bladder

Open wound of scrotum

Fig. 2. Structure of injured organs

The most common injuries were those involving external genital organs. These injuries covered more than half of all cases and the most common diagnosis was external genital contusion ( $\mathrm{S} 30.2$ by ICD-9). Genital injuries grouped by ICD-9 were presented in Table 1.

\begin{tabular}{|l|c|c|}
\hline ICD-10 Diagnosis Code & $\mathrm{n}$ & $\%$ \\
\hline S30.2 Contusion of external genitalia organs & 338 & 65,50 \\
\hline S31.3 Open wound of scrotum and testes & 125 & 24,22 \\
\hline $\begin{array}{l}\text { S38.0 Crushing injury of external genitalia } \\
\text { organs }\end{array}$ & 44 & 8,57 \\
\hline $\begin{array}{l}\text { S38.2 Traumatic amputation of external genital } \\
\text { organs }\end{array}$ & 9 & 1,74 \\
\hline
\end{tabular}

Table 1. Genital injuries grouped by ICD-9

External genital contusion was mainly reported in men $(n=285 ; 84.32 \%)$, the average age was 22 years. The most common mechanisms of injury include: object impact, violence and falls. An open scrotum wound is the second most common injury involving external genitalia. The average age of patients was 30 years 5 months. The main mechanisms include falls, object impacts and injuries caused by other people or animals. One death of the patient was reported.

Renal injuries constituted $29.66 \%(n=277)$ of all analyzed hospitalizations. This type of damage is the second most common in the analyzed material. They mainly concerned men $(n=221)$, which is $79.78 \%$. The average age of patients was 38 years 10 months. Deaths were reported in 6 cases, thus renal injury mortality was $2.17 \%$. The mechanism of injury was determined only in $49.1 \%$ of cases. Table 2 shows the mechanisms of injuries recorded in the analyzed material. 


\begin{tabular}{|l|l|}
\hline Mechanism of injury & \multicolumn{1}{c|}{$\%$} \\
\hline 1.Falls & $36,75 \%$ \\
\hline \multicolumn{1}{|c|}{ a)falls from height } & $13,97 \%$ \\
\hline 2. Accidents & $22,79 \%$ \\
\hline 3. Strikes by objects & $5,14 \%$ \\
\hline 4. Violence & $5,14 \%$ \\
\hline 4. Iatrogenic & $2,94 \%$ \\
\hline 5. Others & $27,20 \%$ \\
\hline
\end{tabular}

Table 2. Mechanisms of renal injuries

The urinary bladder was the fourth most frequently injured organ in the analyzed material. There were 32 such cases $(3.42 \%)$. Injuries concerned mainly men $(n=28)$, the average age of hospitalized patients was 50 years and 2 months. In $12.5 \%$ of cases pelvic fractures were observed, bladder injuries due to falls and accidents were relatively frequent. A separate group were foreign bodies of the bladder, which represented $6.31 \%$ of all cases from the analyzed period. The frequency was similar in women $(\mathrm{n}=27)$ and men $(\mathrm{n}=32)$. The average age was 53 years.

The last group analyzed include urethral injuries. These include 45 cases (5.56\% of all injuries) and were more commonly diagnosed in men $(n=45)$. Iatrogenic causes dominate among the injury mechanism, with accompanying pelvic injuries occurring in $4.4 \%$ of cases. The average age in this group was 56 years 11 months.

\section{Discussion}

As a result of conducted studies it was found that men are five times more frequently injured than women. In the assessed material this ratio was higher than in the data known from the literature. According to Salimi et al., it was about 4 [7], while according to Chouhan et al, renal injury occur about 3 times more often in men [8]. The average age of patients was approx. 33 years and 11 months, additionally $60.1 \%(n=562)$ are patients under 45 years of age.

In the collected material, external injuries to the male genital organs were the most frequent. Their anatomical location and high mobility are considered the main cause [9]. The average age of patients who suffered a genital injury, regardless of its nature, was 25 years. The data collected in the literature also show a tendency of young people to be predisposed to this type of accidents. According to Munter, the peak incidence is between 10 and 30 years of age [10]. A typical mechanism was blunt injury, but penetrating injuries in the form of open scrotum wounds, which occurred in $24.22 \%$ of all cases, should not be ignored. Blunt injuries are dominated by those inflicted by other objects, violence as well as falls and traffic accidents. Similar data are presented in papers analyzing the epidemiology of these injuries [11].

Renal injuries are one of the most common urological injury cases. It is estimated that they represent $1-5 \%$ of all injuries [12]. In the majority of studies, the dominant mechanism is blunt injury, but penetrating injuries should not be overlooked. Iatrogenic injuries occur as a result of PCNL or ESWL urological procedures [13]. In the same study, special attention is paid to communication accidents as the main cause of injuries. Renal injuries are most common in men under 40 years of age [14]. In the material collected, renal injuries were reported in $29.66 \%$ of hospitalizations, the vast majority of which were men. The average age of patients is similar to that known from the literature. 
Only $12.67 \%$ of these injuries were accompanied by injuries in other body regions, which is significantly different from data in other papers, where this percentage is estimated to be as high as $60 \%$ [13]. The mechanism of injury was determined in only $49.09 \%$ of all cases and blunt injuries in the form of falls, accidents and impacts definitely dominate (Table 2).

Urinary injuries are among the rare injuries within the urogenital-tract and represent only $1 \%$ according to the literature. This is due to the small size of urethra, the surrounding of soft tissues and bone structures as well as high mobility. The most frequent damage to the ureter is caused by penetrating injuries [14]. In the collected material only four injuries to urethra, which represents $0.42 \%$ of all injuries, were observed. There were no direct causes of injuries in these cases.

Bladder is relatively rarely damaged, however, these injuries may be associated with disproportionately high mortality rates estimated by Mahat et al. for about 11-22\% [15]. Bladder injuries can be divided into intraperitoneal, extraperitoneal and mixed, with the most frequent types of extraperitoneal. The most common mechanism of injury is blunt (60-85\%), while penetrating injuries represent 15-51\% [15]. Iatrogenic injuries, which most often occur during endoscopic urological procedures, are also worth noting. In the study group, bladder injuries affected $3.43 \%$ of all cases $(n=32)$. In $12.5 \%$ they were associated with pelvic injury, while other causes included falls and accidents. A clear predisposition to male gender is noticeable. No death due to bladder injury was reported.

Urethral injuries, in the literature, are estimated at $4 \%$ of all injuries within the urogenital-tract [16]. They can be divided into posterior and anterior urethritis injuries. They are more common in men, which is clearly related to the anatomical conditions of urethra. The most common is iatrogenic catheter damage, due to traumatic catheterization and lower urinary tract procedures. Nonatherogenic injuries are much less frequent and most often due to blunt injury (anterior catheter) and pelvic fractures (posterior catheter) [5]. In our study, 45 such injuries were diagnosed $(5.56 \%)$, and they were the third most numerous group of injuries. The average age of patients was 56 years and 9 months. The most frequent injuries were iatrogenic (22.22\%), while 2 cases were secondary to pelvic injuries. None of the patients died.

\section{Conclusions}

Injuries to the urogenital-tract most often concern young men, they are relatively rare and their mortality rate is low. External genital trauma is the most common injury to the urogenital-tract, while within the urinary tract the most common is renal injury. Occasionally injuries to other organs of the urinary tract occur. The main mechanism of injury is blunt but within the lower urinary tract the iatrogenic damage plays an important role. 


\section{References}

1. https://ec.europa.eu/eurostat/statistics-explained/index.php?title=Causes_of_death_statistics\#Cause

2. Srrreide K, Epidemiology of major trauma Br J Surg. 2009 Jul;96(7):697-8. doi: 10.1002/bjs.6643

3. Global Health Estimates 2016: Deaths by Cause, Age, Sex, by Country and by Region, 2000-2016. Geneva, World Health Organization; 2018.

4. Kitrey ND, Djakovic N, Gonsalves M, Kuehhas FE, Lumen N, Serafetinidis E, Sharma DM, Summerton DJ Guidelines Associates: ElshoutPJ, Sujenthiran A, Veskimäe E, EAU Guidelines on Urological Trauma 2016, Retrieved from: https://uroweb.org/guideline/prostate-cancer/ /accessed: March 2016/

5. McGeady JB, Breyer BN, Current Epidemiology of Genitourinary Trauma Urol Clin North Am. 2013 Aug;40(3):32334

6. https://lublin.stat.gov.pl/opracowania-biezace/opracowania-sygnalne/ludnosc/stan-i-ruch-naturalny-ludnosci-wwojewodztwie-lubelskim-w-2019-r-, 1,15.html\#

7. Salimi J, Nikoobakht MR, Khaji A, Epidemiology of Urogenital Trauma in Iran Results of the Iranian National Trauma Project Urology Journal Vol.3 No.3 171-174 7.

8. Chouhan JD, Winer AG, Johnson C, Weiss JP, Hyacinthe LM. Contemporary evaluation and management of renal trauma. Can J Urol. 2016;23(2):8191-8197.

9. Deurdulian C, Mittelstaedt CA, Chong WK, Fielding JR, US of acute scrotal trauma: optimal technique, imaging findings, and management. Radiographics. 2007;27:357-69.

10. Munter DW, Faleski EJ, Blunt scrotal trauma:emergency department evaluation and management Am J Emerg Med 1989;7(2):227-234.

11. Aragona F, Pepe P, Patanč D, Malfa P, D'Arrigo L, Pennisi M, Management of severe blunt renal trauma in adult patients: a 10-year retrospective review from an emergency hospital. BJUI Int. 2012;110:744-8 Mar;54(3):423-30.

12. Ząbkowski T, Skiba R, Saracyn M, Zieliński H. Analysis of Renal Trauma in Adult Patients: A 6-Year Own Experiences of Trauma Center. Urology Journal. 2015 Sep;12(4):2276-2279.

13. Gourgiotis S, Germanos S, Dimopoulos N, Vougas V, Anastasiou T, Baratsis Renal Injury: 5-Year Experience and Literature Review S. Urol Int 2006;77:97-103. doi: 10.1159/000093899.

14. Scand J, A review of ureteral injuries after external trauma Trauma ResuscEmerg Med. 2010 Feb 3;18:6. doi: 10.1186/1757-7241-18-6.

15. Mahat Y, Leong JY, Chung, PH, A contemporary review of adult bladder trauma. J Inj Violence Res. 2019;11(2):101-106. doi:10.5249/jivr.v11i2.1069

16. Gomez RG, Ceballos L, Coburn M, Corriere Jr JN, Dixon CM, Lobel B, McAninch J, Consensus statement on bladder injuries. BJU Int. 2004 Jul;94(1):27-32.

17. Mundy AR, et al Urethral trauma. Part I: introduction, history, anatomy, pathology, assessment and emergency management. BJU Int, 2011. 108: 310. 